\title{
SINTESIS OKSIDA GRAFENA TEREDUKSI (rGO) DARI ARANG TEMPURUNG KELAPA (Cocos nucifera)
}

\author{
AhMAd Hidayat $^{1}$, Soni Setiadj ${ }^{*}{ }^{*}$, DAN Eko Prabowo Hadisantoso ${ }^{1}$ \\ ${ }^{1}$ Jurusan Kimia, Fakultas Sains dan Teknologi, UIN Sunan Gunung Djati Bandung, \\ Jl. A. H. Nasution No. 105 Cibiru Kota Bandung \\ *alamat email korespondensi: s.setiadji@uinsgd.ac.id
}

\begin{abstract}
Informasi Artikel Abstrak/Abstract
Riwayat Naskah :

Diterima pada 15

Desember 2018

Diterima setelah

direvisi pada 29

Januari 2019

Diterbitkan pada 30

Januari 2019

Kata Kunci: rGO; modifikasi Hummer; arang tempurung kelapa; grafena; grafit.

Keywords: $r G O$; Hummer modification; coconut shell charcoal; graphene; graphite.

Grafena merupakan satu lapis atom karbon yang memiliki hibridisasi $\mathrm{sp}^{2}$ membentuk struktur heksagonal dua dimensi. Grafena memiliki potensi yang sangat luas namun ketersediaannya masih terbatas. Penelitian ini bertujuan untuk mensintesis oksida grafena tereduksi (rGO) dari arang tempurung kelapa dengan menggunakan metode modifikasi Hummer. Modifikasi dilakukan dengan menghilangkan $\mathrm{NaNO}_{3}$. Sintesis dilakukan dengan ukuran partikel arang tempurung kelapa $\sim 50 \mu \mathrm{m}$ dan waktu oksidasi selama 5 hari. Analisis struktur rGO dilakukan dengan pengujian FTIR, UV-Vis dan difraksi sinar-X (XRD). Hasil pengujian FTIR menunjukkan adanya puncak pada panjang gelombang $1604,891 \mathrm{~cm}^{-1}$ dari ikatan $\mathrm{C}=\mathrm{C}$ aromatik yang merupakan indikasi terbentuknya rGO. Hasil pengujian UV-Vis menunjukkan adanya serapan pada panjang gelombang $272 \mathrm{~nm}$ yang disebabkan oleh transisi $\pi \rightarrow \pi^{*}$ dari ikatan $\mathrm{C}=\mathrm{C}$ pada cincin aromatik. Pengujian XRD menghasilkan puncak difraktogram pada sudut $2 \theta \sim 24^{\circ}$ yang khas untuk material rGO.

Graphene is a layer of carbon atoms, which has $s p^{2}$ hybridization to form a two-dimensional hexagonal structure. Graphene has a very wide potential but its availability is still limited. This study aims to synthesize reduced graphene oxide $(r G O)$ from coconut shell charcoal that using Hummer modification method. The modification was done by eliminated of $\mathrm{NaNO}_{3}$. Synthesis was carried out with particle size of coconut shell charcoal $\sim 50 \mu m$ and oxidation time for 5 days. Analysis of $r G O$ sample was carried out through measured from FTIR, UVVis and X-ray diffraction (XRD). FTIR spectra was show a typical peak from wavelength $1604.891 \mathrm{~cm}^{-1}$ that indicates the $C=C$ aromatic bond, which is an indication to formation of rGO. UV-Vis spectra was shown a absorption at $272 \mathrm{~nm}$ that caused by $\pi \rightarrow \pi^{*}$ transition from $C=C$ bond on aromatic rings. XRD measurement was resulted a peak diffractogram at $2 \theta \sim 24^{\circ}$, which is typical for $r G O$ material.
\end{abstract}

\section{PENDAHULUAN}

Grafena merupakan material karbon dua dimensi yang memiliki sifat yang unik dan luar biasa sehingga memiliki potensi yang cukup besar dalam berbagai aplikasi. Grafena memiliki banyak potensi aplikasi seperti di bidang baterai, pengisi polimer, sensor, konversi energi, dan perangkat penyimpanan energi [1].

Dengan mempertimbangkan potensi dan aplikasi grafena tersebut, sehingga kebutuhan akan grafena akan terus dan perlu ditingkatkan. Grafena menjadi bahan baku yang banyak dicari, akan tetapi ketersediaan grafena masih terbatas, sehingga bagaimana menghasilkan bahan ini dalam jumlah yang banyak menjadi perhatian yang menarik. Salah satunya pengembangan metode sintesis yang sederhana dan efisien untuk pengadaan grafena sangat dibutuhkan.

Metode yang paling banyak digunakan untuk sintesis grafena adalah oksidasi grafit secara kimia. Metode ini melibatkan oksidasi grafit menjadi grafena oksida (GO) menggunakan reagen pengoksidasi kuat, lalu GO dapat dirubah menjadi grafena melalui proses reduksi menggunakan berbagai reduktan. Keuntungan dari metode ini adalah pembentukan grafena dalam jumah besar dalam bentuk serbuk, yang terdispersi baik pada pelarut polar dan pelarut non polar. Oksidasi grafit secara kimia merupakan metode yang menggunakan asam pekat (asam sulfat, asam nitrat, dan asam fosfat) dan agen pengoksidasi kuat (kalium permanganat dan kalium perklorat). Namun, metode oksidasi biasanya membutuhkan beberapa tahapan dan pengendalian suhu oksidasi untuk membuat GO.

Untuk mencapai nilai komersial, proses sintesis GO harus sederhana dan biaya yang murah. Banyak sekali metode yang dapat digunakan untuk memproduksi GO secara oksidasi kimia, seperti metode Hummer, metode Staudeumaier's, dan metode Brodie's [2]. Metode 
Hummer merupakan metode oksidasi kimia yang paling luas digunakan untuk memproduksi GO. Metode Hummer adalah metode oksidasi secara kimia dengan cara mencampurkan serbuk grafit dan $\mathrm{NaNO}_{3}$ ke dalam larutan asam sulfat [3]. Metode ini sangat simpel dan baik sekali untuk menghasilkan GO. Namun, penggunaan $\mathrm{NaNO}_{3}$ dalam metode ini akan menghasilkan gas toksik $\mathrm{NO}_{2}$ dan $\mathrm{N}_{2} \mathrm{O}_{4}$ yang dilepaskan selama proses oksidasi berlangsung.

Pemanfaatan arang tempurung kelapa oleh masyarakat luas selama ini hanya digunakan sebagai arang aktif atau adsorben. Salah satu pemanfatan limbah tempurung kelapa ini memungkinkan untuk digunakan sebagai bahan baku dalam pembuatan grafena oksida yang merupakan bahan baku utama dari grafena. Dalam penelitian ini telah dilakukan sintesis oksida grafena tereduksi (rGO) menggunakan arang tempurung kelapa (Cocos nucifera) melalui metode modifikasi Hummer. Kemudian sampel rGO dikarakterisasi melalui pengukuran difraktometer sinar-X (RINT 2000 wide angle Goniometer, $\mathrm{CuK} \alpha 1,54 \AA$ ), spektrofotometri FTIR (Agilent technologies, type: Carry 600 series), dan Spektrofotometri UV-Vis (Agilent technologies Carry 60 series).

\section{EKSPERIMEN}

\section{Material}

Bahan-bahan yang digunakan dalam penelitian ini adalah arang tempurung kelapa komersil, $\mathrm{H}_{2} \mathrm{SO}_{4}$ (95-98\%, Merck), $\mathrm{KMnO}_{4}$ (Merck), $\mathrm{H}_{2} \mathrm{O}_{2}$ (30\%, Merck), $\mathrm{HCl}$ (37\%, Merck), etanol, dan akua DM.

\section{Instrumentasi}

\begin{abstract}
Difraktometer sinar-X (RINT 2000 wide angle Goniometer, $\mathrm{CuK} \alpha \quad 1,54 \AA)$, spektrofotometri FTIR (Agilent technologies, type: Carry 600 series), dan Spektrofotometri UV-Vis (Agilent technologies Carry 60 series).
\end{abstract}

\section{Prosedur}

\section{Preparasi Sampel}

Arang tempurung kelapa komersil dibersihkan dengan cara dicuci dengan air hingga bersih. Lalu arang tempurung kelapa digerus hingga berbentuk serbuk. Serbuk arang tempurung kelapa kemudian disaring menggunakan saringan $50 \mu \mathrm{m}(\sim 275$ mesh $)$. Arang tempurung kelapa tersebut kemudian di leaching dengan larutan $\mathrm{HCl}$ 0,4 M selama 8 jam. Kemudian dinetralkan dengan akua DM.

\section{Sintesis Oksida Grafena Tereduksi (rGO)}

Oksida grafena tereduksi (rGO) disintesis dengan cara mengoksidasi arang tempurung kelapa berdasarkan metode modifikasi Hummer yang telah dilakukan sebelumnya oleh Chen dkk, 2013 [4].

Serbuk arang tempurung kelapa sebanyak 6 g ditambahkan ke dalam gelas kimia yang berisi asam sulfat pekat $140 \mathrm{~mL}$. Gelas kimia tersebut di simpan di dalam ice-bath, lalu dimasukkan $\mathrm{KMnO}_{4}$ sebanyak $18 \mathrm{~g}$ sedikit demi sedikit supaya suhu campuran tidak melebihi $20^{\circ} \mathrm{C}$, kemudian ditambahkan $300 \mathrm{~mL}$ akua DM. Suspensi kemudian diaduk selama dua jam pada suhu $35^{\circ} \mathrm{C}$.

Selanjutnya, suspensi didiamkan (proses oksidasi) selama 5 hari. Setelah proses oksidasi selesai, tahap selanjutnya adalah menambahkan $500 \mathrm{~mL}$ akua DM dan $\mathrm{H}_{2} \mathrm{O}_{2}$ sebanyak $15 \mathrm{~mL}$ (proses reduksi), dan tahap ini menyebabkan larutan berbuih dan suhu campuran meningkat. Selama tahap ini, warna campuran akan berubah dari coklat gelap ke kuning. Campuran kemudian dicuci dengan larutan $\mathrm{HCl}$ sebanyak $1 \mathrm{~L}(1: 10$ $\mathrm{HCl}$ : akua DM) dengan menggunakan kertas saring dan corong, agar ion logam dapat dihilangkan. Pada tahap ini akan dihasilkan pasta yang kemudian dikeringkan pada suhu $60{ }^{\circ} \mathrm{C}$ selama 6,5 jam, hingga terbentuk padatan, padatan tersebut kemudian didispersikan ke dalam $500 \mathrm{~mL}$ akua DM dan didiamkan selama 3 jam. Pemurnian dilakukan dengan cara mencuci suspensi dengan akua DM dalam jumlah besar. $\mathrm{pH}$ akan meningkat dari 1 hingga 5 selama proses pencucian.

Selanjutnya, pasta yang telah dikumpulkan dari kertas saring didispersikan kedalam $300 \mathrm{~mL}$ air deionisasi kemudian di sonikasi dengan sonikator selama 20 menit. Hasil dispersi berwarna coklat dari oksida grafena tereduksi (rGO) kemudian disentrifugasi pada $4000 \mathrm{rpm}$ selama 30 menit untuk memisahkan grafit oksida yang tidak terkelupas. Setelah proses sentrifugasi, rGO akan berada di dasar wadah, dan proses dekantasi akan terjadi secara gravitasi tanpa ada masalah. Selanjutnya rGO kering akan didapat dengan proses dehidrasi. Tahapan dehidrasi dimulai dengan cara memanaskan rGO pada cawan pada temperatur $30^{\circ} \mathrm{C}$ selama 2 menit, kemudian $40^{\circ} \mathrm{C}$ selama 2 menit, $50^{\circ} \mathrm{C}$ selama 2 menit, dan terakhir $90^{\circ} \mathrm{C}$ selama 1 jam. Serpihan rGO akan diperoleh dengan cara mengerik padatan rGO dari cawan. 


\section{HASIL DAN PEMBAHASAN}

Oksida grafena tereduksi (rGO) telah disintesis menggunakan metode modifikasi Hummer yang disarankan oleh Chen dkk, 2013 [4], dan telah dilakukan ulang dan dioptimasi oleh Johansen dkk, 2014 [5]. Pada modifikasi metode Hummer ini penggunaan $\mathrm{NaNO}_{3}$ dihilangkan. Penghilangan ini bertujuan untuk menghindari terbentuknya gas beracun $\mathrm{NO}_{2}$ dan $\mathrm{N}_{2} \mathrm{O}_{4}$ yang terbentuk selama proses oksidasi.

Sumber karbon yang digunakan pada penelitian ini berasal dari arang tempurung kelapa komersil. Arang tempurung kelapa digerus hingga memiliki ukuran partikel sekitar $50 \mu \mathrm{m}$ (275 mesh) untuk memperbesar luas permukaannya supaya mempermudah proses oksidasi, sehingga akan terjadi proses interkalasi antar lapisan grafena pada grafit [6], lalu dicuci dengan larutan $\mathrm{HCl}$ dan dibilas dengan akua DM berlebih untuk menghilangkan kandungan logam yang terkandung dalam arang tempurung kelapa [7]. Reaksinya dengan $\mathrm{HCl}$ adalah sebagai berikut:

$2 \mathrm{Al}+6 \mathrm{HCl} \rightarrow 2 \mathrm{Al}^{3+}+6 \mathrm{Cl}^{-}+3 \mathrm{H}_{2} \uparrow$

$2 \mathrm{~K}+2 \mathrm{HCl} \rightarrow 2 \mathrm{~K}^{+}+2 \mathrm{Cl}^{-}+\mathrm{H}_{2} \uparrow$

Lalu arang tempurung kelapa dikeringkan melalui proses pemanasan.

Proses sintesis rGO dimulai dengan pembuatan prekursor grafena oksida. Arang tempurung kelapa dalam larutan asam sulfat pekat ditambahkan $\mathrm{KMnO}_{4}$ secara perlahan, sehingga diperoleh grafit yang akan teroksidasi menghasilkan grafit terinkalasi. Interkalasi ini akan menyebabkan jarak antar lapisan grafena membesar dan interaksi antar lapisan melemah [8].

Selain menyempurnakan interkalasi dari grafit dan asam sulfat, penambahan $\mathrm{KMnO}_{4}$ juga membantu dalam oksidasi grafit. Dua reaksi, yaitu pembentukan grafit bisulfat dan oksidasi berlangsung secara serempak. Kalium permanganat adalah salah satu oksidator kuat, terutama dalam suasana asam. Penetrasi $\mathrm{KMnO}_{4}$ ke dalam lapisan grafena sangat efektif untuk mengoksidasi grafit.

Spesies aktif yang bereaksi sebenarnya adalah dimangan heptoksida. Bimetalik heptoksida jauh lebih reaktif daripada nonmetalik tetraoksida. Setelah tahap ini, material awal, serbuk grafit telah berubah menjadi grafit oksida.

Pada proses ini, warna campuran akan berubah warna dari hijau tua keunguan menjadi coklat tua (Gambar 1). Agar proses oksidasi berlangsung sempurna, maka campuran diaduk selama 2 jam pada suhu $35^{\circ} \mathrm{C}$.

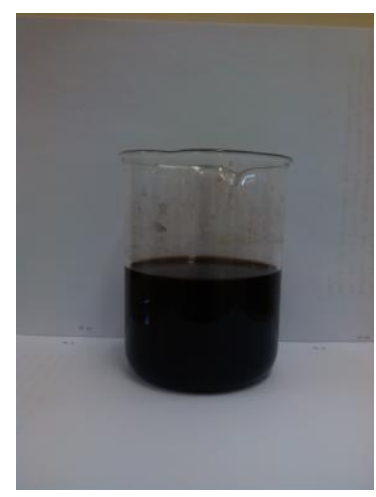

Gambar 1. Warna campuran setelah penambahan $\mathrm{KMnO}_{4}$

Kemudian dilakukan penambahan $300 \mathrm{~mL}$ akua DM secara bertahap. Reaksi antara akua DM dan $\mathrm{H}_{2} \mathrm{SO}_{4}$ merupakan reaksi eksotermik sehingga akan terjadi kenaikan temperatur hingga $98^{\circ} \mathrm{C}$.

Untuk mengurangi efek dari reaksi eksotermik antara akua DM dan $\mathrm{H}_{2} \mathrm{SO}_{4}$, maka proses penambahan akua DM dilakukan terbalik. Campuran yang mengandung larutan $\mathrm{H}_{2} \mathrm{SO}_{4}$ ditambahkan ke dalam akua DM sehingga dapat mengurangi efek eksotermik yang dihasilkan. Selanjutnya campuran dibiarkan selama 5 hari agar proses oksidasi berlangsung secara optimum. Waktu optimasi ini didasarkan pada penelitian sebelumnya yang telah dilakukan oleh Johansen dkk [5].

Setelah proses oksidasi selesai, campuran ditambahkan $500 \mathrm{~mL}$ akua DM dan $\mathrm{H}_{2} \mathrm{O}_{2}$ untuk menghentikan proses oksidasi. Ketika hidrogen peroksida ditambahkan, residu permanganat dan mangan dioksida direduksi menjadi larutan tak berwarna mangan sulfat dan warnanya akan berubah dari hitam kecoklatan menjadi kuning.

Proses selanjutnya yaitu proses pencucian. Proses ini menggunakan larutan $\mathrm{HCl}$ encer dengan perbandingan 1:10 ( $\mathrm{HCl}$ : akua $\mathrm{DM})$. Tujuan dari proses ini yaitu untuk menghilangkan ion logam sisa yang dihasilkan selama proses oksidasi. Kemudian pasta dicuci dengan akua DM berlebih, pencucian ini dilakukan untuk meningkatan $\mathrm{pH}$. $\mathrm{pH}$ berpengaruh terhadap sifat hidrofilik grafena oksida. Oleh karena itu dapat diperoleh sifat yang diinginkan pada $\mathrm{pH}$ 7. Pada $\mathrm{pH}$ rendah gugus karboksil terprotonisasi seperti lembaran grafena menjadi kurang hidrofilik dan terbentuk agregat. Pada $\mathrm{pH}$ tinggi gugus karboksil terdeprotonisasi sehingga sangat hidrofilik seperti lembaran-lembaran individu (terpisah) yang lebih larut dalam air seperti garam-garam [5].

Oksida grafena tereduksi (rGO) diperoleh dengan menggunakan proses sonikasi. Penggunaan sonikasi bertujuan untuk 
mendispersikan pasta kedalam air agar grafit oksida terkelupas. Pengelupasan ini dapat terjadi karena adanya gelombang ultrasonik. Gelombang ultrasonik merupakan salah satu dari gelombang mekanik dengan range frekuensi lebih dari $20.000 \mathrm{~Hz}$ sehingga proses pengelupasan dari grafit oksida menjadi grafena oksida dilakukan secara mekanik. Proses pengelupasannya diawali dengan adanya gaya geser pada grafit oksida akibat interaksi dengan gelombang ultrasonik dan proses kavitasi disebabkan karena adanya perbedaan tekanan pada saat sonikasi sehingga menyebabkan inisiasi proses pengelupasan grafit oksida menjadi grafena oksida.

Setelah proses pengelupasan secara mekanik dengan sonikasi, suspensi disentrifugasi untuk memisahkan grafena oksida dan grafit oksida yang tidak terkelupas. Oksida grafena tereduksi (rGO) akan didapat dengan mudah melalui proses gravitasi tanpa ada masalah. Oksida grafena tereduksi (rGO) akan berada di dasar wadah setelah proses sentrifugasi (Gambar 2).

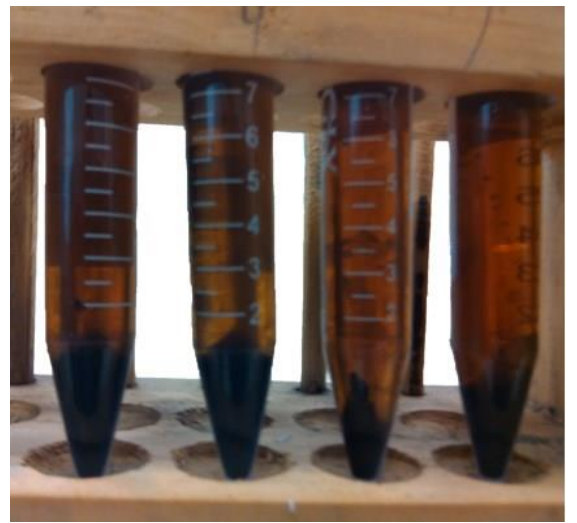

Gambar 2. Oksida grafena tereduksi (rGO) mengendap secara gravitasi

Setelah proses sentrifugasi, pasta rGO dipindahkan ke dalam cawan. Kemudian dilakukan pemanasan di dalam oven pada suhu $90^{\circ} \mathrm{C}$. Sebagai hasil dari tahap ini, air dipindahkan dan lembaran-lembaran grafena oksida tereduksi (rGO) dapat dikerik.

\section{Hasil pengujian rGO menggunakan FTIR}

Pengujian Fourier Transform - Infrared (FTIR) dilakukan untuk mengetahui gugus fungsi yang terbentuk selama proses sintesis. Pengujian ini menggunakan FTIR dari Agilent Technologies tipe carry 600 series dengan range panjang gelombang dari $400-4000 \mathrm{~cm}^{-1}$.

Pada proses reduksi grafena oksida menjadi $\mathrm{rGO}$, hal yang harus diperhatikan adalah hilangnya gugus fungsi yang mengandung oksigen setelah proses oksidasi. Gugus $\mathrm{OH}$ yang terdapat dalam grafena oksida akan tereduksi. Hal ini menyebabkan hilangnya pita serapan pada panjang gelombang $3400 \mathrm{~cm}^{-1}$ yang merupakan pita serapan hasil vibrasi ulur dari gugus $\mathrm{OH}$ [9]. Selain itu, pembentukan rGO akan menyebabkan hilangnya pita serapan pada panjang gelombang disekitar $984 \mathrm{~cm}^{-1}$ dan terdapatnya pita serapan pada panjang gelombang disekitar $1628 \mathrm{~cm}^{-1}$ yang merupakan panjang gelombang dari ikatan $\mathrm{C}=\mathrm{C}$ aromatik. Ikatan $\mathrm{C}=\mathrm{C}$ aromatik merupakan indikasi terbentuknya $\mathrm{rGO}$ [8].

Gambar 3 menunjukkan hasil analisis arang tempurung kelapa dan rGO menggunakan FTIR. Seperti yang diharapkan, spektrum FTIR dari rGO mirip dengan spektrum FTIR dari grafit. Oksida grafena tereduksi (rGO) dan grafit memiliki ikatan dan gugus fungsi yang sama. Hal yang perlu diperhatikan disini adalah lemahnya absorpsi dari ikatan $\mathrm{OH}$ pada panjang gelombang $3400 \mathrm{~cm}^{-1}$. Gugus fungsi oksigen biasanya memberikan ikatan yang kuat. Ikatan yang kuat biasanya ditandai dengan dalamnya lembah yang dihasilkan pada spektrum FTIR [10]. Meskipun begitu, sulit untuk membuat kesimpulan berdasarkan persentase dari transmitan karna hal tersebut sangat dipengaruhi oleh banyaknya sampel saat pengujian, dan hal tersebut tidak terkontrol dengan baik [5].

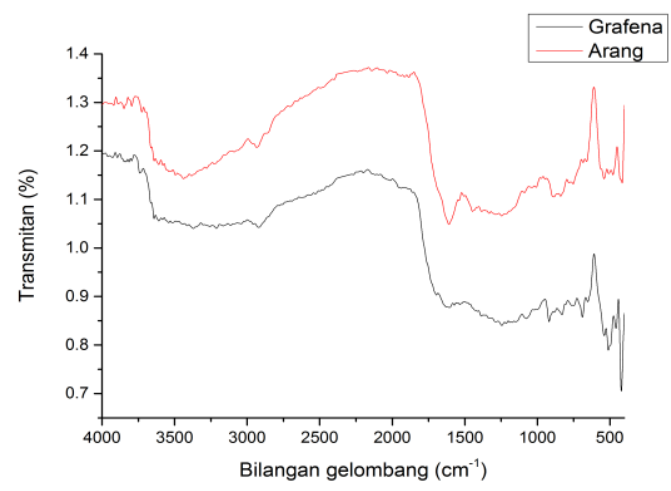

Gambar 3. Spektrum FTIR grafena (rGO) dari arang tempurung kelapa

Serapan pada panjang gelombang $1604,8919 \mathrm{~cm}^{-1}$ menunjukkan adanya puncak dari ikatan $\mathrm{C}=\mathrm{C}$ aromatik. Ikatan $\mathrm{C}=\mathrm{C}$ aromatik merupakan indikasi terbentuknya rGO [8] [11]. Serapan pada panjang gelombang $1720 \mathrm{~cm}^{-1}$ menunjukkan adanya puncak dari serapan $\mathrm{C}=\mathrm{O}$ yang disebabkan oleh pita serapan hasil dari vibrasi ulur dari gugus keton yang terdapat dalam lapisan rGO. Serapan pada panjang gelombang $1074,762 \mathrm{~cm}^{-1}$ menunjukkan adanya pita serapan hasil dari vibrasi ulur gugus $\mathrm{C}-\mathrm{O}$ yang merupakan sisa dari gugus karbonil selama proses reduksi [9]. Dari spekta FTIR juga dapat dilihat bahwa 
tidak adanya pita serapan pada pada panjang gelombang $3400 \mathrm{~cm}^{-1}$ yang merupakan pita serapan hasil vibrasi ulur dari gugus $\mathrm{OH}$. Hal ini menunjukkan bahwa grafena oksida telah tereduksi menjadi lapisan oksida grafena tereduksi (rGO) [5].

Hasil dari analisis menggunakan FTIR menunjukkan masih adanya pita serapan pada panjang gelombang yang mengandung gugus oksigen yang menunjukkan bahwa proses reduksi berlangsung kurang sempurna. Namun secara keseluruhan, hasil dari analisis menggunakan FTIR menunjukkan bahwa sebagian besar gugus fungsi yang mengandung oksigen yang terdapat dalam grafena oksida berhasil dihilangkan.

Grafena oksida dan oksida grafena tereduksi (rGO) memilki spektrum FTIR yang hampir mirip, oleh karena itu spektrum FTIR tidak cukup untuk membedakan apakah sampel merupakan grafit, grafena oksida, atau rGO. Untuk itu dibutuhkan hasil karakterisasi menggunakan XRD untuk menentukan fasa apa yang terbentuk.

\section{Hasil pengujian rGO menggunakan UV-VIS}

Pengujian sampel menggunakan instrumen spektrofotometri UV-Vis dilakukan untuk mengukur jumlah ikatan rangkap atau konjugasi aromatik dari material rGO. Jumlah ikatan rangkap atau konjugasi tersebut disebabkan oleh transisi $\pi \rightarrow \pi^{*}$ dan $n \rightarrow \pi^{*}$ dari sistem konjugasi pada suatu molekul. Spektroskopi UV-Vis secara umum dapat membedakan diena terkonjugasi dan diena tidak terkonjugasi, diena terkonjugasi dari triena terkonjugasi dan sebagainya [10]. Pengujian ini menggunakan UV-Vis dari Agilent Technologies carry 60 dengan range panjang gelombang dari $200-400 \mathrm{~cm}^{-1}$.

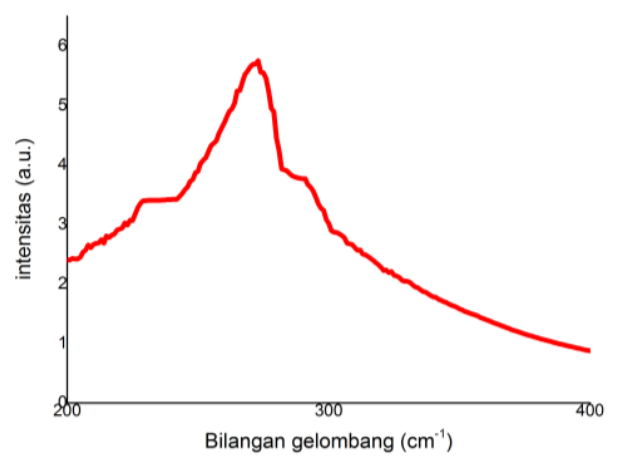

Gambar 4. Spektrum UV-Vis oksida grafena tereduksi (rGO) dari tempurung kelapa

Gambar 4 menunjukkan hasil pengujian material rGO menggunakan spektrometri UVVis. SpektrumUV-Vis menunjukkan bentuk pita serapan pada panjang gelombang $272 \mathrm{~nm}$, yang mana berasal dari serapan yang disebabkan oleh transisi $\pi \rightarrow \pi^{*}$ dari ikatan $\mathrm{C}=\mathrm{C}$ pada cincin aromatik.

Daerah serapan dari transisi elektron yang disebabkan oleh transisi $\pi \rightarrow \pi^{*}$ berada panjang gelombang 200-300 $\mathrm{cm}^{-1}$. Adanya pita serapan pada panjang gelombang $272 \mathrm{~nm}$ menunjukkan serapan oksida grafena tereduksi (rGO). Hal ini sesuai dengan penelitian sebelumnya tentang rGO yang dilakukan oleh Krishnamoorthy dkk [11].

\section{Hasil pengujian $r G O$ menggunakan XRD}

Pengujian menggunakan difraksi sinar-X (XRD) bertujuan untuk menentukan fasa kristalinitas dari grafena oksida tereduksi (rGO). Pengujian dilakukan dengan range sudut $2 \theta$ antara $10-80^{\circ}$ dan panjang gelombang sebesar $1,54 \AA$.

Difraksi sinar-X penting dilakukan untuk menentukan apakah sampel merupakan grafit, grafena oksida atau rGO. Grafit dan rGO memiliki pita $2 \theta$ pada $26-28^{\circ}$, sedangkan grafena oksida memiliki pita $2 \theta$ pada $10-12^{\circ}$ [11] [12].

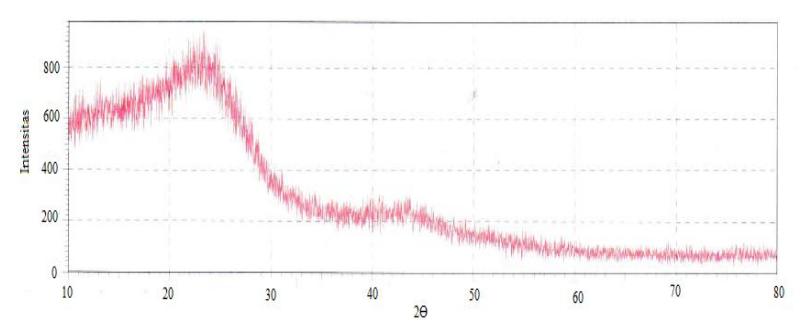

Gambar 5. Difraktogram rGO dari arang tempurung kelapa

Hasil pengujian sampel menggunakan XRD seperti yang ditunjukan pada Gambar 5, menunjukkan adanya pita pada sudut $2 \theta$ sebesar $24^{\circ}$ dan $43^{\circ}$.

Berdasarkan penelitian sebelumnya yang dilakukan oleh Prasetya dkk [7], Setiadji dkk [13] dan Krishnamoorthy dkk [11], fasa rGO memiliki pita pada sudut $2 \theta$ sebesar $25^{\circ}$ dan $45^{\circ}$. Oleh karena itu dari data tersebut dapat dipastikan bahwa sampel tersebut merupakan rGO. Adanya perbedaan sudut $2 \theta$ terjadi karena masih adanya pengotor dari gugus fungsi hidroksil dan karbonil yang disebabkan karena proses reduksi yang tidak sempurna sehingga menyebabkan pergeseran puncak ke sebelah kiri.

Berdasarkan pita difraktogram, rGO yang dihasilkan memiliki fasa amorf. Perbedaan pita difraktogram untuk fasa amorf dan kristalin dapat dilihat dari bentuk pita, apakah pita tersebut tajam atau melebar. 


\section{SIMPULAN}

Oksida grafena tereduksi (rGO) dapat disintesis dengan menggunakan metode modifikasi Hummer, dengan ukuran partikel arang tempurung kelapa sebesar $50 \mu \mathrm{m}$ dan waktu oksidasi selama 5 hari. Oksida grafena tereduksi (rGO) hasil sintesis telah dikarakterisasi menggunakan XRD dan FTIR, menghasilkan puncak difraktogram dan pita serapan dari gugus fungsi yang khas untuk rGO. Hasil pengujian UV-Vis menunjukkan adanya serapan pada panjang gelombang $272 \mathrm{~nm}$ yang disebabkan oleh transisi $\pi \rightarrow \pi^{*}$ dari ikatan $\mathrm{C}=\mathrm{C}$ pada cincin aromatik.

\section{REFERENSI}

[1] P Russo, A Hu, and $\mathrm{G}$ Compagnini, "Synthesis, Properties and Potenial Aplications of Porous Graphene : A Review," Nano-Micro Letters, vol. 5, no. 4, pp. 260-273, 2013.

[2] N M Huang, H N Lim, C H Chia, M A Yarmo, and M R Muhamad, "Simple RoomTemperature Preparation of High Yield Graphene Oxide," DovePress, pp. 34433448, 2011.

[3] W S Hummers Jr and R E Offeman, "Preparation of Graphitic Oxide," Jornal of American Chemical Society, vol. 80, no. 6, pp. 1339-1339, 1958.

[4] J Chen, B Yao, C Li, and G Shi, "An Improved Hummers Metode foe EcoFriendly Synthesis of Grafena Oxide," Carbon, vol. 64, pp. 225-229, 2013.

[5] I Johansen, "Wet Chemicals Ssynthesis of Graphene for Battery Aplications," Trondheim, 2014.

[6] N E Sorokina, M A Khaskov, V V Avdeev, and I V Nikol'skaya, "Reaction of Graphite With Sulfuric Acid in the Presence of $\mathrm{KMnO}_{4}, "$ Rusian Journal of General Chemistry, vol. 75, no. 2, pp. 162-168, 2005.
[7] F A Prasetya, M Nasrullah, A Y Nugraheni, and Darminto, "Study of raman Spectroscopy on Graphene Phase from Heat Treatment of Coconut (Cocus nucifera) shell," Trans Tech Publications, vol. 827, pp. 290-293, 2015.

[8] L N Azizah and D Susanti, "Pengaruh Variasi Kadar $\mathrm{Zn}$ dan Temperatur Hydrothermal terhadap Struktur dan Nilai Konduktivitas Material Graphene," JURNAL TEKNIK POMITS, vol. 3, no. 2, pp. 209214, 2014.

[9] $\mathrm{F}$ T Thema, E D Dikio, M J Moloto, M Khenfouch, N N Nyangiwe, L Kotsedi, and M Maaza, "Synthesis and Characrerization of Graphene Thin Film via Hummer's Method," NSTI-Nanotech, vol. 1, pp. 13-16, 2012.

[10] U Suparman, Elusidasi Struktur Senyawa Organik. Bandung: Widya Padjajaran, 2010.

[11] K Krishnamoorthy, R Veeravandian, R Mohan, and S J Kim, "Investigation of Raman and Photoluminescene of Reduced Graphene Oxide Sheets," Applied Physcs A, vol. 106, pp. 501-506, 2011.

[12] D R Cooper, B D'Anjou, N Ghattamaneni, B Harack, M Hilke, A Horth, N Majlis, M Massicotte, L Vandsburger, E Whiteway, and $\mathrm{V} \mathrm{Yu}$, "Experimental Review of Graphene," Montreal, 2011.

[13] S Setiadji, B W Nuryadin, H Ramadhan, C D D Sundari, T Sudiarti, A Supriadin, and A L Ivansyah, "Preparation of reduced Graphene Oxide (rGO) Assisted by Microwave Irradiation and Hydrothermal for Reduction Methods.," IOP Conf. Series: Materials Science and Engineering, vol. 1, p. 434, 2018. 